\title{
Diferentes dosadores de sementes e velocidades de deslocamento na semeadura do milho em plantio direto
}

\author{
Different seed feeder system and seeding speed in \\ no-tillage corn
}

Laboratório de Geotecnologias Aplicadas ã Produção Agrícola (GeoAPA), Universidade Federal de Santa Maria (UFSM), Rua Ernesto Barros, 1345, CEP 96506-322. Cachoeira do Sul, RS, Brasil

${ }^{2}$ Agropecuária Tramujas Ltda, Campo Mourão, PR, Brasil

${ }^{3}$ Universidade Federal de Santa Catarina (UFSC), Curitibanos, SC, Brasi IInstituto Federal Catarinense (IFC), Rio do Sul, SC, Brasil

* autor correspondente $\checkmark$ bottega.elb@gmail.com

\section{Eduardo Leonel Bottega ${ }^{1 *}$, Thiago Vian², Naiara Guerra ${ }^{3}$, Antonio Mendes de Oliveira Neto ${ }^{4}$}

RESUMO: A uniformidade de distribuição de sementes no solo e a velocidade de semeadura estão diretamente relacionadas à qualidade de implantação de uma lavoura e, consequentemente, com a sua produtividade. Este trabalho objetivou avaliar o desempenho de duas semeadoras-adubadoras equipadas com diferentes mecanismos dosadores de sementes (disco horizontal perfurado e sistema pneumático) em três velocidades de semeadura (4 km, $6 \mathrm{~km}$ e $8 \mathrm{~km} \mathrm{~h}^{-1}$ ) na implantação de uma lavoura de milho em sistema de plantio direto. O experimento foi conduzido em 2013, na Fazenda Agropecuária Tramujas, localizada no município de Luiziana, PR. O delineamento experimental adotado foi o inteiramente casualizado, em esquema fatorial 3 x 2 (3 velocidades de deslocamento e 2 sistemas dosadores de sementes), com 4 repetições. Foram avaliados o índice de velocidade de emergência de plântulas (IVE), por meio do acompanhamento da emergência dessas, e a distribuição longitudinal de sementes, por meio da verificação do espaçamento entre plântulas na linha de semeadura (falho, aceitável e múltiplo). A utilização do dosador pneumático resultou em melhor formação de estande, diminuindo os espaçamentos falhos e duplos e favorecendo a velocidade de emergência de plântulas. O aumento na velocidade de deslocamento do conjunto ocasionou falhas na distribuição longitudinal de sementes, aumentando a ocorrência de espaçamentos falhos e duplos.

PALAVRAS-CHAVE: Zea mays, distribuição de sementes, estande de plantas, velocidade de emergência.
ABSTRACT: The uniformity distribution of seeds and seeding speed are directly related to the quality of a crop implantation and consequently, its yield. This study evaluated the performance of two seeders, equipped with different dispensing mechanisms seeds (perforated horizontal disc and pneumatic system) in three seeding speeds (4, 6 and $8 \mathrm{~km} \mathrm{~h}^{-1}$ ) the implementation of a maize crop in no-till system. The experiment was conducted in 2013, at Tramujas Farm, located in Luiziana city, Paraná state, South region, Brazil. The experimental design was a completely randomized in a factorial design $3 \times 2$ (three seeding speeds and two seed feeder system) with four replications. They evaluated the seedling emergence speed index (ESI) by monitoring the emergence of these and longitudinal distribution of seeds by checking the spacing between seedlings in the sowing line (flawed, acceptable and multiple). The use of pneumatic system resulted in better stand training, reducing outages and double spacing and promoting seedling emergence speed. The increase in the overall speed of displacement caused failures in the longitudinal distribution of seeds, increasing the defective and double spacing.

KEYWORDS: Zea mays, seed distribution, plants stand, emergence speed.

\section{Introdução}

De acordo com a Companhia Nacional de Abastecimento (CONAB), na temporada 2016/17 a produção total de milho no Brasil foi de aproximadamente 97 milhões de toneladas. A Região Centro-Sul apresentou a maior participação, contribuindo com $90,5 \%$ da produção nacional. Na Região Sul, a produção 
de milho na safra $2016 / 17$ foi de 27,1 milhões de toneladas, sendo o Estado do Paraná o maior produtor (17,8 milhões de toneladas), seguido pelo Rio Grande do Sul (6 milhões de toneladas) e Santa Catarina, com 3,3 milhões de toneladas (COMPANHIA..., 2017).

O estande de plantas é um dos fatores que influenciam diretamente a produtividade da cultura do milho, sendo sua uniformidade dependente da precisão da semeadora-adubadora na distribuição uniforme das sementes na linha de cultivo. As semeadoras adubadoras podem ser providas de diferentes mecanismos dosadores de sementes, sendo os mais utilizados na semeadura do milho o disco perfurado horizontal e o dosador pneumático. Esses dosadores diferem na precisão de distribuição uniforme de sementes na linha de semeadura, o que implica em diferentes arranjos espaciais de plantas no campo.

A uniformidade de distribuição de sementes no solo tem sido colocada na literatura como estratégia de aumento da produtividade de determinadas culturas (PINHEIRO NETO et al., 2008), sendo esse fator influenciado pela velocidade de semeadura e pelo sistema dosador de sementes. Bottega et al. (2014) avaliaram o efeito da profundidade e da velocidade de semeadura na implantação da cultura do milho em sistema de plantio direto e concluíram que o incremento na velocidade de semeadura, de $3 \mathrm{~km}$ para $9 \mathrm{~km} \mathrm{~h}^{-1}$, ocasionou aumento na porcentagem de espaçamentos falhos e múltiplos bem como redução nos espaçamentos aceitáveis, corroborando estudo realizado por Garcia et al. (2006).

Estudando a distribuição longitudinal de sementes de milho em função do tipo de dosador de sementes e da velocidade de deslocamento da semeadora-adubadora, Oliveira et al. (2009) concluíram que o dosador pneumático apresentou melhor desempenho na distribuição longitudinal de sementes de milho e que a uniformidade de distribuição não foi afetada significativamente pela velocidade de deslocamento. Resultado semelhante foi observado por Pinheiro Neto et al. (2008), que concluíram em sua pesquisa que independentemente da velocidade de semeadura o dosador pneumático apresentou desempenho superior quanto aos espaçamentos aceitáveis, quando comparado ao dosador mecânico.

Este trabalho teve como objetivo avaliar a uniformidade na distribuição longitudinal de sementes de milho de duas semeadoras-adubadoras, uma equipada com dosador de sementes pneumático e outra do tipo disco perfurado horizontal, operando em três velocidades de semeadura.

\section{Material e Métodos}

$\mathrm{O}$ experimento de campo foi conduzido na Fazenda Agropecuária Tramujas, localizada no município de Luiziana, PR, propriedade do sr. Sidnei Likes Penteado, localizada na BR 158, $\mathrm{km} 28$, distrito de Campina do Amoral, latitude 24¹4'24" Sul, longitude $52^{\circ} 22^{\prime} 07^{\prime \prime}$ Oeste e altitude de 654 metros acima do nível do mar. O clima da região é classificado como Cfa, subtropical, de temperatura média no mês mais frio inferior a $18^{\circ} \mathrm{C}$ e temperatura média no mês mais quente acima de $22^{\circ} \mathrm{C}$, com verões quentes, geadas pouco frequentes e tendência a concentração de chuvas nos meses de verão, entretanto sem estação seca definida, segundo a classificação de Köppen
(INSTITUTO..., 2012). O solo da área é classificado como Latossolo Vermelho Distroférrico (EMPRESA..., 2005).

$\mathrm{Na}$ operação de semeadura, foram utilizadas duas semeadoras-adubadoras. A primeira, modelo John Deere 1111, equipada com dosador de sementes pneumático, 10 linhas espaçadas em $0,50 \mathrm{~m}$. A máquina possui capacidade para armazenagem de $1.500 \mathrm{~kg}$ de adubo e $500 \mathrm{~kg}$ de semente. A largura útil de trabalho é de $5 \mathrm{~m}$. A segunda, modelo Tatu Marchesan Ultra Flex 11, equipada com dosador de sementes tipo disco perfurado horizontal, com as mesmas especificações técnicas da primeira semeadora em relação a capacidade de armazenagem de adubo e semente e largura útil de trabalho.

$\mathrm{Na}$ implantação do experimento, utilizou-se sulcador de adubo tipo facão, sendo os depósitos de adubo e sementes mantidos à meia carga durante a implantação. Para tracionar as semeadoras, utilizaram-se dois modelos de tratores. A semeadora-adubadora John Deere foi tracionada por um trator de mesma marca modelo 7225J, 4 x 4, com $225 \mathrm{cv}$ de potência no motor. Já a semeadora Ultra Flex 11 foi tracionada por um trator da marca New Holland modelo TM 135, 4 x 4, com $135 \mathrm{cv}$ de potência no motor.

Foi semeado híbrido simples de milho da Pioneer (30F53 HX), de ciclo precoce ( 870 unidade de grau dia - GDU), grão duro avermelhado, recomendado para a época e o local onde se realizou o experimento. A semeadura foi realizada no dia 1 de outubro de 2012, seguindo zoneamento agroclimático da cultura do milho no Paraná, conforme a classificação do híbrido escolhido (INSTITUTO..., 2012). A densidade populacional utilizada foi de 84 mil plantas por hectare. Para fertilização, utilizaram-se $400 \mathrm{~kg}$ de adubo pré-formulado NPK $(10-26-10)$.

As variáveis testadas foram três velocidades de deslocamento do conjunto mecanizado e dois sistemas dosadores de sementes. O delineamento experimental utilizado foi o inteiramente casualizado, em esquema fatorial $3 \times 2$ ( 3 velocidades de deslocamento e 2 sistemas de dosadores de sementes), com 3 repetições. As velocidades testadas foram $4 \mathrm{~km}, 6 \mathrm{~km} \mathrm{e} 8 \mathrm{~km} \mathrm{~h}^{-1}$ e dosadores de sementes pneumático e de disco perfurado horizontal. As 3 velocidades combinadas com os 2 sistemas compuseram 6 tratamentos. Cada parcela experimental foi composta por 5 linhas espaçadas em 0,5 metro com 20 metros de comprimento, totalizando uma área de $50 \mathrm{~m}^{2}$. A área útil de cada parcela foi representada pelas 3 linhas centrais, descontando-se 3 metros de cada extremidade, o que correspondeu a uma área de $21 \mathrm{~m}^{2}$.

Avaliou-se, para cada tratamento, o índice de velocidade de emergência de plântulas (IVE) e a distribuição longitudinal de sementes. O IVE foi contabilizado utilizando-se o método proposto por Maguire (1962), pelo qual o índice de velocidade de emergência de plântulas é avaliado em um comprimento de 3 metros nas linhas centrais, deixando uma bordadura de $2 \mathrm{~m}$ de cada parcela (Equação 1). A contagem das plântulas emergidas foi realizada, a cada 2 dias até o $16^{\circ}$ dia após a semeadura.

$$
I V E=\frac{E_{1}}{N_{1}}+\frac{E_{2}}{N_{2}}+\ldots \frac{E_{n}}{N_{n}}
$$

em que:

IVE - índice de velocidade de emergência;

E1, E2, En - número de plântulas emergidas, na primeira, segunda, ..., última contagem; 
$\mathrm{N} 1, \mathrm{~N} 2, \mathrm{Nn}$ - número de dias da semeadura à primeira, segunda, ..., última contagem.

A verificação da germinação das sementes, dos espaçamentos entre as plântulas, bem como da germinação obtida para a quantidade de sementes depositadas foi realizada 19 dias após a semeadura. Levantou-se o número de ocorrências de deposição de múltiplos, falhos e aceitáveis e comparou-se esses números com as recomendações agronômicas do espaçamento entre sementes para a cultura utilizada, de acordo com a norma ABNT (ASSOCIAÇÃO...,1995): milho, espaçamento de 22,7-23,9 cm. Na Tabela 1 são apresentados os intervalos obtidos, utilizando-se 23,9 cm como espaçamento de referência (Xref).

Os dados referentes aos parâmetros avaliados foram submetidos à análise de variância e as médias testadas pelo teste de Tukey a 5\% de probabilidade. Utilizou-se o software Assistat nas análises estatísticas.

\section{Resultados e Discussão}

Na Tabela 2 é apresentado o resumo da análise de variância para o Índice de Velocidade de Emergência (IVE) em função do tipo de dosador de sementes utilizado, velocidade de deslocamento do conjunto mecanizado e da interação entre eles. $\mathrm{O}$ coeficiente de variação (CV) observado para os diferentes tratamentos foi de $0,73 \%$. Pode-se observar que todos os fatores estudados, inclusive a interação entre eles, afetaram de forma significativa o IVE.

Viganó et al. (2008), estudando a influência da velocidade de semeadura e de diferentes mecanismos sulcadores do solo sobre o índice de velocidade de emergência de milho, não observaram diferenças significativas para o IVE. Esses resultados concordam com os obtidos por Reis et al. (2006), possivelmente devido à uniformidade na profundidade de deposição das sementes no sulco de semeadura.

O teste de médias para os valores de índice de velocidade de emergência (IVE) em função do dosador utilizado, da velocidade de semeadura e da interação dosador versus velocidade é apresentado na Tabela 3 .

O valor médio de IVE observado para o dosador pneumático foi maior e diferiu estatisticamente do valor observado para o dosador tipo disco horizontal perfurado. Um fato que pode explicar essa diferença está associado à forma de seleção da semente utilizada pelo mecanismo dosador pneumático, a seleção e individualização de sementes por meio de pressão negativa. Esse sistema de seleção causa menores danos às sementes, isso porque apresenta número menor de componentes mecânicos envolvidos no processo.

Sementes que sofrem danos no processo de semeadura perdem vigor, reduzindo-se, com isso, sua velocidade de emergência. Segundo Villiers (1973), a perda de vigor nas sementes que sofreram danos pode ser explicada pela necessidade de reorganização dos tecidos e organelas danificados delas pouco antes de dar início ao crescimento do eixo embrionário, retardando a emergência das plântulas.

Vale et al. (2010) demonstram o potencial que o mecanismo dosador tipo disco horizontal perfurado têm de causar danos a sementes. Estudando a influência da velocidade de deslocamento
Tabela 1. Intervalos de referência para os espaçamentos entre plântulas (ASSOCIAÇÃO..., 1995).

\begin{tabular}{cc}
\hline Tipo de espaçamento & Intervalo de tolerância para X \\
\hline Múltiplo $<$ 0,5 Xref & $\mathrm{X}<\mathbf{1 1 , 9 5}$ \\
$\mathbf{0 , 5}$ Xref $<$ Aceitável $>1,5$ Xref & $11,95<\mathrm{X}>\mathbf{3 5 , 8 5}$ \\
Falho $>$ 1,5 Xref & $\mathrm{X}>\mathbf{3 5 , 8 5}$ \\
\hline
\end{tabular}

Xref: Espaçamento de referência equivalente a $23,9 \mathrm{~cm}$.

Tabela 2. Análise de variância para o Índice de Velocidade de Emergência (IVE) em função da utilização de diferentes dosadores e velocidades de deslocamento.

\begin{tabular}{ccccr}
\hline $\begin{array}{c}\text { Fator de } \\
\text { variação }\end{array}$ & GL & SQ & QM & F \\
\hline Dosadores (D) & 1 & $\mathbf{0 , 5 3}$ & $\mathbf{0 , 5 3}$ & $\mathbf{6 3 2 , 2 4 * *}$ \\
Velocidades (V) & 2 & $\mathbf{0 , 0 5}$ & $\mathbf{0 , 0 2}$ & $29,55 * *$ \\
DxV & 2 & $\mathbf{0 , 0 4}$ & $\mathbf{0 , 0 2}$ & $23,39 * *$ \\
Tratamentos & 5 & $\mathbf{0 , 6 2}$ & $\mathbf{0 , 1 2}$ & $\mathbf{1 4 7 , 6 3 * *}$ \\
Resíduo & 12 & $\mathbf{0 , 0 1}$ & $\mathbf{0 , 0 0 0 8 4}$ & \\
Total & 17 & $\mathbf{0 , 6 3}$ & & \\
\hline
\end{tabular}

GL - Grau de Liberdade; SQ - Soma de quadrados; QM - Quadrado médio; $\mathrm{F}$ - Valor do teste $\mathrm{F}$ de Snedcor; ${ }^{*}$ Significativo ao nível de $1 \%$ de probabilidade $(\mathrm{p}<0,01)$

Tabela 3. Teste de médias para os valores de Índice de Velocidade de Emergência (IVE) em função do dosador utilizado, da velocidade de semeadura e da interação dosador versus velocidades.

\begin{tabular}{|c|c|c|c|c|}
\hline \multirow{2}{*}{ Dosador } & \multicolumn{3}{|c|}{ Velocidades $\left(\mathrm{km} \mathrm{h}^{-1}\right)$} & \multirow{2}{*}{ Médias } \\
\hline & 4 & 6 & 8 & \\
\hline Pneumático & $4,05 \mathrm{aC}$ & $4,25 \mathrm{aA}$ & $4,14 \mathrm{aB}$ & $4,15 \mathrm{~A}$ \\
\hline $\begin{array}{c}\text { Disco horizontal } \\
\text { perfurado }\end{array}$ & $3,75 \mathrm{bB}$ & $3,77 \mathrm{bB}$ & $3,89 \mathrm{bA}$ & $3,80 \mathrm{~B}$ \\
\hline Médias & $3,90 \mathrm{~b}$ & $4,01 \mathrm{a}$ & $4,01 \mathrm{a}$ & \\
\hline
\end{tabular}

Médias seguidas pela mesma letra, maiúscula na coluna e minúscula na linha, não diferem estatisticamente entre si, teste de Tukey ao nível de $5 \%$ de probabilidade.

no desempenho de uma semeadora-adubadora direta, os autores concluíram que o mecanismo dosador da máquina diminuiu, em média, 2,8\% a germinação das sementes, quando comparado com o valor observado das sementes que não passaram pelo mecanismo, fato esse explicado por danos causados ao embrião.

A utilização do dosador pneumático apresentou maior IVE quando comparada a do dosador disco horizontal perfurado, sendo o maior valor observado para velocidade de deslocamento de $6 \mathrm{~km} \mathrm{~h}^{-1}$. Resultado contrário foi observado por Faganello et al. (1998) e Mello et al. (2007), estudando a influência da velocidade de semeadura sobre o índice de emergência de plântulas. Segundo os autores, a velocidade de semeadura não influenciou na emergência de plântulas, pois para as variáveis diretamente ligadas a produtividade, tais como massa de grãos na espiga e produtividade de grãos houve interação entre velocidades e híbridos, ou seja, não se pode afirmar que o aumento de velocidade na operação de semeadura causou desarranjos no espaçamento longitudinal das sementes e no IVE, e que esse desarranjo levou à diminuição da produtividade. 
Na Tabela 4 é apresentada a análise de variância do levantamento de plantas falhas em função da utilização de diferentes dosadores e velocidades de deslocamento. O coeficiente de variação $(\mathrm{CV})$ foi de $11,33 \%$.

Observou-se que os mecanismos dosadores de sementes e as velocidades de semeadura afetaram significativamente o número de plantas falhas na implantação da cultura do milho. A interação entre os fatores não apresentou influência significativa. Dias et al. (2009) observaram, ao estudar os efeitos da velocidade de semeadura sobre a distribuição longitudinal de sementes para diferentes densidades populacionais de milho, que o aumento da velocidade reduziu o percentual de espaçamentos aceitáveis, aumentando o de espaçamentos falhos. O mesmo efeito foi observado por outros estudos (MELLO et al., 2003; LIU et al., 2004; MAHL et al., 2004), os quais verificaram efeito negativo do aumento da velocidade de trabalho na distribuição de sementes de milho, expresso pela redução do percentual de aceitáveis.

$\mathrm{Na}$ Tabela 5 é apresentado o resultado do teste de médias para os valores de plantas falhas em função do dosador utilizado, da velocidade de semeadura e da interação dosador versus velocidade.

O dosador tipo disco horizontal perfurado apresentou maior média, estatisticamente significativa, de plantas falhas. O mesmo foi observado para a maior velocidade de semeadura $\left(8 \mathrm{~km} \mathrm{~h}^{-1}\right)$. A interação entre dosadores e velocidades de semeadura não apresentou diferenças significativas.

Estudos realizados por Mahl et al. (2004) concluíram que a velocidade de deslocamento na operação de semeadura da cultura do milho interferiu na distribuição longitudinal de plantas e no índice de precisão da distribuição das plantas, sendo os melhores resultados observados para velocidade de semeadura inferiores a $8,1 \mathrm{~km} \mathrm{~h}^{-1}$. O mesmo foi observado por Garcia et al. (2006) e Bottega et al. (2014). O aumento de plantas falhas em função do aumento da velocidade de deslocamento também foi observado por estudos conduzidos por Mello et al. (2003) e Liu et al. (2004). Os autores verificaram efeito negativo do aumento da velocidade de deslocamento na distribuição de sementes de milho, expresso pela redução do percentual de espaçamento aceitável entre plantas.

A elevação da capacidade operacional propiciada pelo uso de velocidades de deslocamento mais elevadas pode comprometer a qualidade da semeadura (LIU et al., 2004; DIAS et al., 2009), haja visto que, com o aumento da velocidade de semeadura, reduz-se o tempo disponível para preenchimento dos furos dos discos dosadores. Entretanto Klein et al. (2002) afirmam que maiores velocidades de semeadura não afetaram a distribuição de plantas de soja.

Na Tabela 6 é apresentada a análise de variância do levantamento de plantas duplas em função da utilização de diferentes dosadores e velocidades de deslocamento. O coeficiente de variação (CV) foi de 13,52\%. Apenas o fator velocidade de semeadura apresentou influência estatisticamente significativa para a variável planta dupla.

$\mathrm{Na}$ Tabela 7 é apresentado o teste de médias para os valores de plantas duplas em função do dosador utilizado, da velocidade de semeadura e da interação dosador versus velocidades. A média de plantas falhas aumentou significativamente com o aumento da velocidade de semeadura, não sendo influenciada pelo tipo de mecanismo dosador de sementes.

Tabela 4. Análise de variância do levantamento de plantas falhas em função da utilização de diferentes dosadores e velocidades de deslocamento.

\begin{tabular}{ccccc}
\hline Fator de variação & GL & SQ & QM & F \\
\hline Dosadores (D) & $\mathbf{1}$ & $\mathbf{0 , 5 8}$ & $\mathbf{0 , 5 8}$ & $\mathbf{2 3 , 6 1 * *}$ \\
Velocidades (V) & 2 & 1,34 & $\mathbf{0 , 6 7}$ & $\mathbf{2 7 , 1 0 * *}$ \\
DxV & 2 & $\mathbf{0 , 0 6}$ & $\mathbf{0 , 0 3}$ & $\mathbf{1 , 1 6}^{\mathrm{ns}}$ \\
Tratamentos & $\mathbf{5}$ & $\mathbf{1 , 9 8}$ & $\mathbf{0 , 4 0}$ & $\mathbf{1 6 , 0 3 * *}$ \\
Resíduo & 12 & $\mathbf{0 , 3 0}$ & $\mathbf{0 , 0 2}$ & \\
Total & 17 & $\mathbf{2 , 2 8}$ & & \\
\hline
\end{tabular}

GL - Grau de Liberdade; SQ - Soma de quadrados; QM - Quadrado médio; F - Valor do teste F de Snedcor; **Significativo ao nível de $1 \%$ de probabilidade $(\mathrm{p}<0,01)$; ns: não significativo $(\mathrm{p} \geq 0,05)$.

Tabela 5. Teste de médias para os valores de plantas falhas em função do dosador utilizado, da velocidade de semeadura e da interação dosador versus velocidades.

\begin{tabular}{|c|c|c|c|c|}
\hline \multirow{2}{*}{ Dosadores } & \multicolumn{3}{|c|}{ Velocidades $\left(\mathrm{km} \mathrm{h}^{-1}\right)$} & \multirow{2}{*}{ Médias } \\
\hline & 4 & 6 & 8 & \\
\hline Penumático & $0 \mathbf{a A}$ & $0 \mathbf{a A}$ & $1,67 \mathrm{aA}$ & 0,56 B \\
\hline $\begin{array}{c}\text { Disco horizontal } \\
\text { perfurado }\end{array}$ & 0,67 aA & 1,33 aA & $2,67 \mathrm{aA}$ & $1,56 \mathrm{~A}$ \\
\hline Médias & 0,33 b & $0,67 \mathrm{~b}$ & $2,17 \mathrm{a}$ & \\
\hline
\end{tabular}

Médias seguidas pela mesma letra, maiúscula na coluna e minúscula na linha, não diferem estatisticamente entre si, teste de Tukey ao nível de $5 \%$ de probabilidade.

Tabela 6. Análise de variância do levantamento de plantas duplas em função da utilização de diferentes dosadores e velocidades de deslocamento.

\begin{tabular}{ccrrr}
\hline Fatores de variação & GL & SQ & \multicolumn{1}{c}{ QM } & \multicolumn{1}{c}{ F } \\
\hline Dosadores (D) & 1 & 0,07 & 0,07 & $2,26^{\text {ns }}$ \\
Velocidades (V) & 2 & 150,55 & 0,75 & $25,54 * *$ \\
DxV & 2 & 0,06 & 0,03 & 1,01 ns \\
Tratamentos & 5 & 163,18 & 0,33 & $11,07 * *$ \\
Resíduo & 12 & 0,35 & 0,03 & \\
Total & 17 & 1,99 & & \\
\hline
\end{tabular}

GL - Grau de Liberdade; SQ - Soma de quadrados; QM - Quadrado médio; F - Valor do teste F de Snedcor; $* *$ Significativo ao nível de $1 \%$ de probabilidade $(\mathrm{p}<0,01)$; ns: não significativo $(\mathrm{p} \geq 0,05)$.

Tabela 7. Teste de médias para os valores de plantas duplas em função do dosador utilizado, da velocidade de semeadura e da interação dosador versus velocidades.

\begin{tabular}{ccccc}
\hline \multirow{2}{*}{ Dosadores } & \multicolumn{3}{c}{ Velocidades $\left(\mathrm{km} \mathrm{h}^{-1}\right)$} & \multirow{2}{*}{ Médias } \\
\cline { 2 - 4 } & 4 & 6 & 8 & \\
\hline $\begin{array}{c}\text { Penumático } \\
\text { Disco horizontal } \\
\text { perfurado }\end{array}$ & $0 \mathrm{aA}$ & $0 \mathrm{aA}$ & $1,67 \mathrm{aA}$ & $0,56 \mathrm{~A}$ \\
Médias & $0 \mathrm{aA}$ & $0,67 \mathrm{aA}$ & $2 \mathrm{aA}$ & $0,89 \mathrm{~A}$ \\
\hline
\end{tabular}

Médias seguidas pela mesma letra, maiúscula na coluna e minúscula na linha, não diferem estatisticamente entre si, teste de Tukey ao nível de 5\% de probabilidade. 
Estudos realizados por Dambrós (1998) evidenciaram, assim como neste estudo, que a distribuição de sementes apresenta expressivo aumento de plantas duplas quando ocorre o aumento da velocidade. De acordo com estudos realizados por Mahl et al. (2004), a elevação da velocidade da semeadura reduz a qualidade da distribuição, proporcionando aumento na ocorrência de plantas duplas.

\section{Conclusões}

O mais adequado IVE observado foi para o dosador pneumático com velocidade de deslocamento de $6 \mathrm{~km} \mathrm{~h}^{-1}$.

$\mathrm{O}$ aumento da velocidade de deslocamento na semeadura do milho interfere na precisão e na distribuição das plantas.

A distribuição de plantas mais adequada foi obtida ao se utilizar o dosador de sementes pneumático nas velocidades $4 \mathrm{~km} \mathrm{e} 6 \mathrm{~km} \mathrm{~h}^{-1}$.

A ocorrência de plantas duplas está relacionada diretamente com o aumento da velocidade de semeadura.

\section{Referências}

ASSOCIAÇÃO BRASILEIRA DE NORMAS TÉCNICAS - ABNT. Projeto de norma 04:015.06-007: semeadora - semeadora-adubadora - ensaios de campo - método de ensaio. São Paulo: ABNT, 1995. 12 p.

BOTTEGA, E. L. et al. Efeitos da profundidade e velocidade de semeadura na implantação da cultura do milho. Pesquisa Agropecuária Pernambucana, Recife, v. 19, n. 2, p. 74-78, 2014.

COMPANHIA NACIONAL DE ABASTECIMENTO - CONAB. Acompanhamento da safra brasileira de grãos: Acompanhamento da safra brasileira de grãos, Safra 2017/18 - Primeiro levantamento. Vol. 5, n. 1. Brasília: CONAB, 2017, 114 p.

DAMBRÓS, R. M. Avaliação do desempenho de semeadorasadubadoras de milho com diferentes mecanismos dosadores. 1998. 86 f. Dissertação (Mestrado em Máquinas Agrícolas)-Escola Superior de Agricultura "Luiz de Queiroz", Universidade de São Paulo, Piracicaba, 1998.

DIAS, V. O. D. et al. Distribuição de sementes de milho e soja em função da velocidade e densidade de semeadura. Ciência Rural, Santa Maria, v. 39, n. 6, p. 1721-1728, 2009.

EMPRESA BRASILEIRA DE PESQUISA AGROPECUÁRIA - EMBRAPA; CENTRO NACIONAL DE PESQUISAS DE SOLOS - CNPS. Sistema brasileiro de classificação de solos. 2. ed. Brasília: Embrapa Produção da Informação; Rio de Janeiro: Embrapa Solos, 2005. 412 p.

FAGANELLO, A.; SATTLER, A.; PORTELA, J. A. A eficiência de semeadoras na emergência de plântulas de milho (Zea mays L.) sob o sistema de plantio direto. In: CONGRESSO BRASILEIRO DE ENGENHARIA AGRÍCOLA, 27., 1998. Poços de Caldas.
Anais... Poços de Caldas: Sociedade Brasileira de Engenharia Agrícola, 1998. p. 229-231.

GARCIA, L. C. et al. Influência da velocidade de deslocamento na semeadura do milho. Engenharia Agrícola, Jaboticabal, v. 26, n. 2, p. 520-527, 2006.

INSTITUTO AGRONÔMICO DO PARANÁ - IAPAR. Cartas climáticas do Paraná. Disponível em: <http://www.iapar.br/modules/ conteudo/conteudo.php?conteudo=597>. Acesso em: 10 out. 2012.

KLEIN, V. A. et al. Efeito da velocidade na semeadura direta da soja. Engenharia Agrícola, Jaboticabal, v. 22, n. 1, p. 75-82, 2002.

LIU, W. et al. Impact of planter type, planting speed, and tillage on stand uniformity and yield of corn. Agronomy Journal, Madison, v. 96, n. 6, p. 1668-1672, 2004.

MAGUIRE, J. D. Speed of germination-aind in selection and evaluation for seedling emergence and vigor. Crop Science, v. 2, p. 176-177, 1962.

MAHL, D. et al. Demanda energética e eficiência da distribuição de sementes de milho sob variação de velocidade e condição de solo. Engenharia Agrícola, Jaboticabal, v. 24, n. 1, p. 150-157, 2004.

MELLO, A. J. R. et al. Produtividade de híbridos de milho em função da velocidade de semeadura. Engenharia Agrícola, Jaboticabal, v. 27, n. 2 , p. $479-486,2007$.

MELLO, L. M. M. et al. Distribuição de sementes e produtividade de grãos da cultura do milho em função da velocidade de semeadura e tipos de dosadores. Engenharia Agrícola, v. 23, n. 3, p. 563-567, 2003.

OLIVEIRA, L. G. et al. Distribuição longitudinal de sementes de milho em função do tipo de dosador de sementes e velocidade de deslocamento. Cultivando o Saber, Cascavel, v. 2, n. 1, p. 140-146, 2009.

PINHEIRO NETO, R. et al. Desempenho de mecanismos dosadores de sementes em diferentes velocidades e condições de cobertura do solo. Acta Scientiarum Agronomy, Maringá, v. 30, p. 611-617, 2008. Suplemento.

REIS, E. F. et al. Densidade do solo no ambiente solo-semente e velocidade de emergência em sistema de semeadura de milho. Revista Brasileira de Ciências do Solo, Viçosa, v. 30, p. 777-786, 2006.

VALE, W. G. et al. Influência da velocidade de deslocamento no desempenho de uma semeadora-adubadora direta. Global Science and Technology, Rio Verde, v. 3, n. 3, p. 67-74, 2010.

VIGANÓ, J. P. et al. Velocidade de emergência na cultura do milho em função da velocidade de deslocamento e mecanismos sulcadores. Cultivando o Saber, Cascavel, v. 1, n. 1, p. 7-16, 2008.

VILLIERS, T. A. Ageing and longevity of seeds in field conditions. In: Heydecker, W. (Ed.). Seed ecology. London: The Pennsylvania State University Press, p. 265-288, 1973.

Recebido: 30 set. 2015 Aprovado: 02 jan. 2018 